\title{
DESIGN METHOD OF WINCH DRIVEN BY CONTACTLESS MAGNETIC COUPLING UNDER DEEPWATER
}

\author{
B. Zhang ${ }^{\text {a }}$ \\ Z. Wanga ${ }^{c}$ \\ T.Wang \\ H.J. Yu ${ }^{\mathrm{a}}$ \\ ${ }^{a}$ College of Mechanical and Electrical Engineering, Harbin Engineering University, China

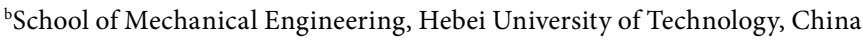 \\ ${ }^{\mathrm{c}}$ College of Mechanical and Electrical Engineering, Jilin University of chemical technology, China
}

\begin{abstract}
Through the combination subject of scientific research, the design method of the winch driven by contactless magnetic coupling is researched for the core purpose of the turning shaft sealing in a deepwater environment. This method has six design phases, including domestic and foreign information query and retrieval, graphic analyses of relevant structures, innovative design of $2 D$ assembly sketches, a theoretical computation of structure parameters, the $3 D$ modeling and motion simulation and engineering drawing. This method is of generality, which can provide examples for the postgraduate students and engineering personnel in self-renovation design of scientific research.
\end{abstract}

Keywords: magnetic coupling, winch, graph analysis, CAD

\section{INTRODUCTION}

The deepwater pipeline's tieback technology belongs to the deepwater oil and gas exploitation technology. We can make good use of the existing facility when the new development oilfield pass through the production pipeline and merge into the established establishedestablishedestablishedestablishedestablishednetwork of pipe lines, so it will make the little boundary oilfield's exploitation around the main oilfield become effective and economic. In order to complete tieback work between the two connecting pipeline under the sea, we need to measure the distance and the pose between the middle of the two pipe flange. People can prefabricate a length of transition pipe which fit the two hard pipe's connection on board [1]. We call this kind of measuring technology as a deep-sea pipeline pose measurement technology. It is not much study in our country. But there are mainly the divers assisted rope measuring system; ROV auxiliary rope measuring system and acoustic measurement system in foreign companies, so in order to achieve this technology becoming percentage of home-made parts and research on independent innovation, the project has been listed as national " 863 " key projects in $2006[2,3]$. The winch is the key equipment in the drawstring measurement system. But bottleneck problem is the deep rotation axis seal problem. This paper will use magnetic coupling nonmetallic materials to study in dynamic sealing drive scheme.

\section{METHOD FOR DETERMINING THE WINCH DESIGN SCHEME}

It is the most important stage to ensure the design of the scheme in the research of scientific research project. It directly affects the success of the project study. Therefore, it will cost a 
longer period of time for the planner to analysis and research.

First of all, put the research project and the solve problem into technological classification. We can only have a definite object in view to formulate solutions under the background of full understanding of the relevant technical institute of technology.

Secondly, this paper summarizes the technique according to the check information at home and abroad. The winch of this measurement system belongs to the hoisting rope drum category, it plays a role as to tighten up or loosen the measuring cable, and the lifting rope drum is used in different depth $(1500 \sim 15000 \mathrm{~m})$ under the sea. It needs to solve the motor output shaft seal of underwater moving bottleneck problem. So it needs to retrieval the underwater sealing technology.

Finally, we should creative the thinking according to the query data. We can take the progressive layer by layer, interlocking questioning manner analysis. The design scheme of the winch use the motor drive and non metallic magnetic transmission can be fully enclosed motor static sealing, bearing the pressure more than $150 \mathrm{MPa}$, at the same time; the rotation of the motor is transferred to the external drive the reel to rotate by magnetic force [4].

\section{STRUCTURE DESIGN METHOD OF THE WINCH}

For the winch's design, the magnetic transmission for the design is of the core. From the information available to the German Fluid Systems Co., Ltd. (GFS) produced for the coupled magnetic stirrer corrosion, inflammable, explosive environments. The three-dimensional structure model is shown in fig.1. The assembly and the disassembly analysis conducted by the three-dimensional structure model in fig.1. Interpreting the images from right to left side, the flange from the left site and the isolation of the motor (part4) cover the right flange connection of part 1 into a whole through the bolt closed part 7. The output shaft of the motor through the key and the inner magnetic rotor (part2) connection is sealed in the isolation cover (part 1) isolated from the outside world. the outer magnetic rotor (part6) and impeller (part5) connected by a sliding bearing isolation cover (part1) fixed on the left axis, thus, the output shaft of the motor drives the inner rotor (part2) turn to the part3, transferring to the outside through the magnetic coupling magnetic rotor (part6), The external magnetic rotor (part6) drives the stirring wheel (part5) rotating mixing corrosive materials.

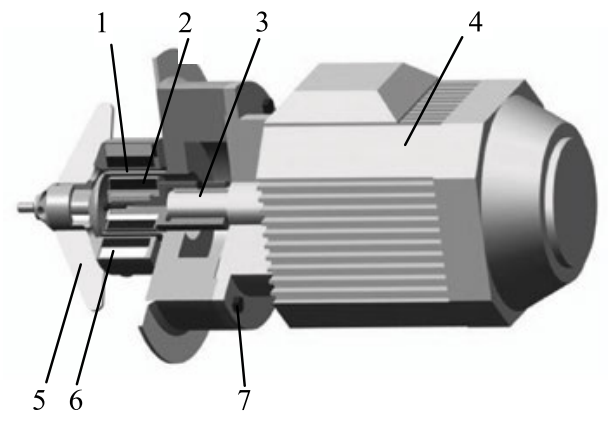

Fig.1 Magnetic coupling blender of a German company
There are two methods the assembly in mechanical drawing, painting respectively from outside to inside and from inside to outside. According to the three-dimensional model of foreign graphic assembly analysis, we can determine the assembly design winch that is taken from inside to outside. So the magnetically-couple's local assembly is the main line. Using graphics software such as CAD, CAXA, and 2D assembly drawing design is shown in fig. 2 on the computer.

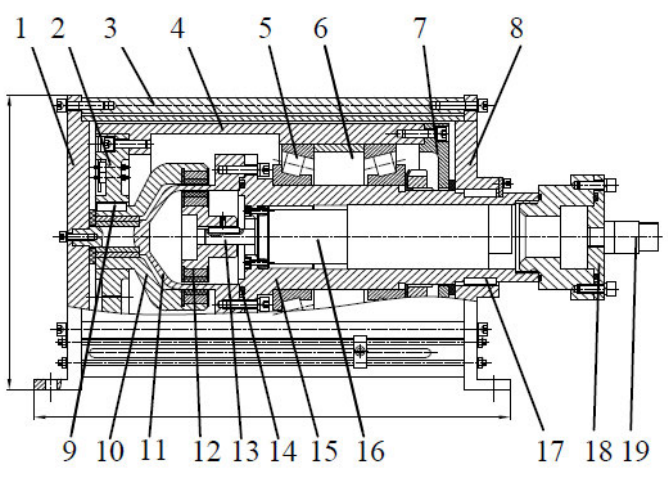

Fig.2 Winch 2D assembly structure

\section{STRUCTURE PARAMETERS OF THE WINCH}

The rope winch as the measurement vector rope measuring system is used in addition to erect its gravity and is also supported from the impact load, water buoyancy. Thus, we select the stainless steel wire rope, specifications: $6 \mathrm{X} 7+\mathrm{IWS}$ round strand, nominal diameter $\mathrm{d}: 3 \mathrm{~mm}$, the minimum breaking force, weight: $6.37 \mathrm{kN}$ theory, $3.7 \mathrm{~kg} / 100 \mathrm{~m}$.

In the measurement of the deepwater, the wire rope needs to pass through the stretching tight, so making a similar cable tension structure. As shown in fig.3, the rope's two points is A, B, height difference is $C$, span $\mathrm{L}$.

For the analysis of the suspension mechanism theory, it usually must meet the following two conditions: (1) the cable is the ideal flexible, neither compression, not bending. (2) The cable material is in accordance with Hooke's law. The analysis of the wire rope tension of suspension structure can be used in the calculation of single cable theory. For the analysis of the internal force of steel wire rope, we intercept in a very small part as dx, the force analysis of it is as shown in fig. 4 the differential unit. Because the steel rope is equivalent to the ideal flexible suspension, so the rope's tension tangent the curve with a differential unit direction of $\mathrm{T}$, taking the horizontal component of $\mathrm{H}$, and the tension's T angle is $\theta$, the vertical component is

$$
\mathrm{V}=\mathrm{Htg} \theta=\mathrm{H} \frac{\mathrm{dz}}{\mathrm{dx}}
$$



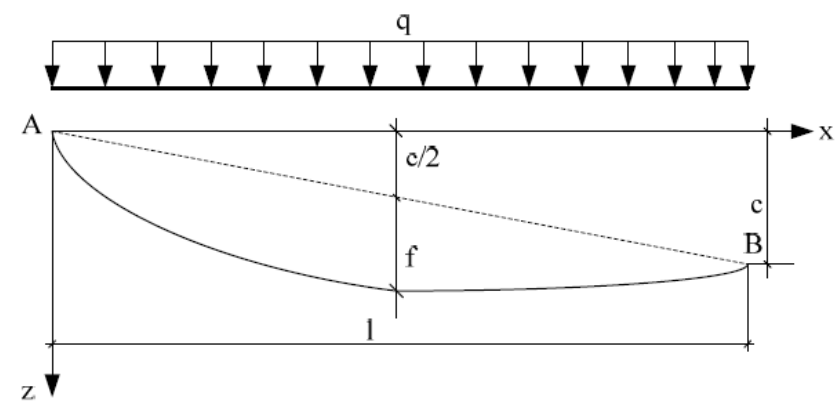

Fig. 3 The gravity loads distributed along the span steel wire

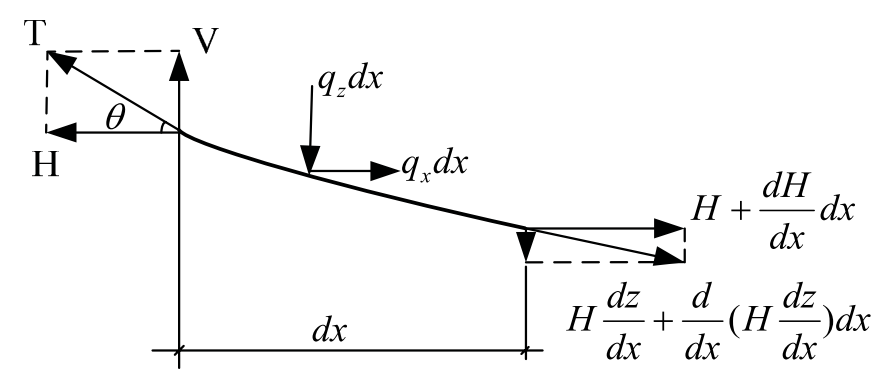

Fig. 4 Force analysis of wire rope differential unit

According to the condition of the static equilibrium differential unit can be listed as follows and be listed as follows the wire rope balance equation.

$$
\begin{gathered}
\sum X=0, \frac{d H}{d x} d x+q_{x} d x=0 \\
\frac{d H}{d x}+q_{x}=0 \\
\sum Z=0, \frac{d}{d x}\left(H \frac{d z}{d x}\right) d x+q_{z} d x=0 \\
\frac{d}{d x}\left(H \frac{d z}{d x}\right)+q_{z}=0
\end{gathered}
$$

Due to external force is only considered the gravity load distribution, so $q_{x}=0$, equation (2) can be written as

$$
\mathrm{H} \frac{\mathrm{d}^{2} \mathrm{z}}{\mathrm{dx}^{2}}+\mathrm{q}=0
$$

After the integral two times, we can get:

$$
\mathrm{z}=-\frac{\mathrm{q}}{2 \mathrm{H}} \mathrm{x}^{2}+\mathrm{C}_{1} \mathrm{x}+\mathrm{C}_{2}
$$

By the equation form we know that this is a parabola, we can determine the integration constants $C_{1}, C_{2}$ by further defining boundary conditions. According to fig. $3, X=0, z=0, x=1, z=c$, $\mathrm{C}_{2}=0$. EQ (4) after finishing the parabolic equation is obtained.

$$
z=\frac{q}{2 H} x(1-x)+\frac{c}{1} x
$$

By the formula (5), when the gravity load of wire rope distributes along the span, the shape of wire rope is a parabola. When the wire rope span and the length of two support points are equal, the shape of the parabolic is determined by the horizontal tension $\mathrm{H}$ and the vertical distributed load $\mathrm{q}$.

For the same wire rope between $\mathrm{A}$ and $\mathrm{B}$, the parabolic equation can be determined as long as the horizontal tension $\mathrm{H}$ of the wire rope is known. Similarly, if the parabolic equation of the wire rope is known, the horizontal tension can be obtained. As shown in fig. 3 , the sag of the wire rope in the span midpoint is $\mathrm{f}$. That is:

$$
\mathrm{x}=\frac{1}{2}, \quad \mathrm{z}=\frac{\mathrm{c}}{2}+\mathrm{f}
$$

Put the result into the formula (5), the horizontal tension can be obtained:

$$
\mathrm{H}=\frac{\mathrm{q}^{2}}{8 \mathrm{f}}
$$

According to the formula (7), the horizontal tension is proportional $\mathrm{H}$ to the vertical distributed load $\mathrm{q}$ and is inversely proportional to the sag $f$ which reflects the stretch degree of the wire rope. These are consistent with the actual situation.

When the curve equation of wire rope $\mathrm{z}(\mathrm{x})$ is determined, the tension $\mathrm{T}$ of each point can be obtained by the following formula (8) according to the previous analysis:

$$
\mathrm{T}=\mathrm{H} \sqrt{1+\left(\frac{\mathrm{dz}}{\mathrm{dx}}\right)^{2}}
$$

By the formula (5), we can obtain:

$$
\frac{d z}{d x}=-\frac{4 f}{1}\left(1+\frac{c}{4 f}-\frac{2 x}{1}\right)
$$

Therefore, the tension $\mathrm{T}$ of wire rope is

$$
T=H \sqrt{1+\frac{16 f^{2}}{1^{2}}\left(1+\frac{c}{4 f}-\frac{2 x}{1}\right)^{2}}
$$

According to the formula (10), it is easy to know when the $\mathrm{x}$ is equal to $1 / 2$; the tension force of wire rope has a maximum value Tmax.

$$
\mathrm{T}_{\max }=\mathrm{H} \sqrt{1+\frac{16 \mathrm{f}^{2}}{1^{2}}\left(1+\frac{\mathrm{c}}{4 \mathrm{f}}\right)^{2}}
$$

When the sag $\mathrm{f}$ compared with the span 1 is a very small value, it is far less than the span 1 , so the tension $\mathrm{T}$ is equal to the horizontal tension $\mathrm{H}$. 
Tab. 1 The tension value of wire rope corresponding to different sag

\begin{tabular}{|c|c|c|c|c|c|c|}
\hline \multirow{2}{*}{$\mathbf{D}$} & \multirow{2}{*}{$\mathbf{F}_{\text {bmin }}$} & \multicolumn{5}{|c|}{$\mathbf{T}$} \\
\cline { 2 - 7 } & $\mathbf{k N}$ & \multicolumn{4}{|c|}{$\mathbf{N}$} \\
\hline $\mathrm{mm}$ & & $f=500$ & $f=1000$ & $f=1500$ & $f=2000$ & $f=2500$ \\
\hline 1.0 & 1.03 & 10.40 & 7.37 & 6.03 & 5.23 & 4.68 \\
\hline 1.5 & 1.99 & 20.39 & 14.45 & 11.81 & 10.24 & 9.17 \\
\hline 2.0 & 3.38 & 34.75 & 24.62 & 20.13 & 17.45 & 15.63 \\
\hline 2.5 & 5.45 & 56.18 & 39.80 & 32.54 & 28.22 & 25.27 \\
\hline 3.0 & 7.28 & 65.95 & 46.72 & 38.20 & 33.13 & 29.67 \\
\hline
\end{tabular}

As shown in the Tab.1, it gives the tension value of wire rope corresponding to different sag $\mathrm{f}$. In the Tab.1, D is the outside diameters of wire rope, Fbmin is the minimum breaking force of wire rope, $\mathrm{T}$ is the tension of wire rope.

From these data given in the Tab.1, it can be seen that the tension of wire rope corresponding to different sag is far less than the minimum breaking force of wire rope, which proves the result meets the strength requirement.

By using the tension value $\mathrm{T}$, we can obtain the motor power $\mathrm{P}$ of the winding wire rope. The motor power can be determined by the following formula:

$$
P=T \times V
$$

By the formula (5), we can obtain the required motor power corresponding to different sag for 30 meters wire rope with different diameter, as shown in Tab. 2.

Similar to the tension of wire rope, the motor power $P$ of the winding wire rope relates to the outside diameters $\mathrm{D}$ of wire rope and the sag $f$ of wire rope. The greater is the diameter, the bigger the sag, and the higher the power.

For example, if $\mathrm{d}=3 \mathrm{~mm}, \mathrm{f}=1500 \mathrm{~mm}$, the corresponding motor power $\mathrm{P}=46.72 \mathrm{w}$.

Tab. 2 the required motor power corresponding to different sag

\begin{tabular}{|c|c|c|c|c|c|}
\hline \multirow{2}{*}{$\mathbf{D}$} & \multicolumn{5}{|c|}{ T } \\
\cline { 2 - 6 } & \multicolumn{5}{|c|}{$\mathbf{N}$} \\
\hline $\mathrm{mm}$ & $f=500$ & $f=1000$ & $f=1500$ & $f=2000$ & $f=2500$ \\
\hline 1.0 & 10.40 & 7.37 & 6.03 & 5.23 & 4.68 \\
\hline 1.5 & 20.39 & 14.45 & 11.81 & 10.24 & 9.17 \\
\hline 2.0 & 34.75 & 24.62 & 20.13 & 17.45 & 15.63 \\
\hline 2.5 & 56.18 & 39.80 & 32.54 & 28.22 & 25.27 \\
\hline 3.0 & 65.95 & 46.72 & 38.20 & 33.13 & 29.67 \\
\hline
\end{tabular}

\section{WINCH THREE-DIMENSIONAL MODEL AND ITS MOVEMENT SIMULATION}

When the structure parameters of the system are determined, the main view of two-dimensional assembly sketches needs to be modified and refined before the design of three-dimensional model. But some designers and graduate students eager to obtain the three-dimensional model and miss this step, which cause the three-dimensional model inaccuracy. The case brings difficulty for analysis of quality characteristics, interference checking and motion simulation, which makes the accuracy of two-dimensional engineering graphics low when the three-dimensional model are converted to two-dimensional engineering graphics. In this case, we have to re-make the engineering graphics and face the situation of heavy workload and inefficiency.

The design process of winch three-dimensional model is as follows: when the structure parameters are determined, we need to determine the details of the main view of assembly sketches in fig.2, and then we can construct the winch threedimensional model from the two-dimensional assembly sketches by the outside-in approach through three-dimensional design software, such as pro-E, Solid works, Inverter, UG and so on, as shown in fig. $5[5,6]$.

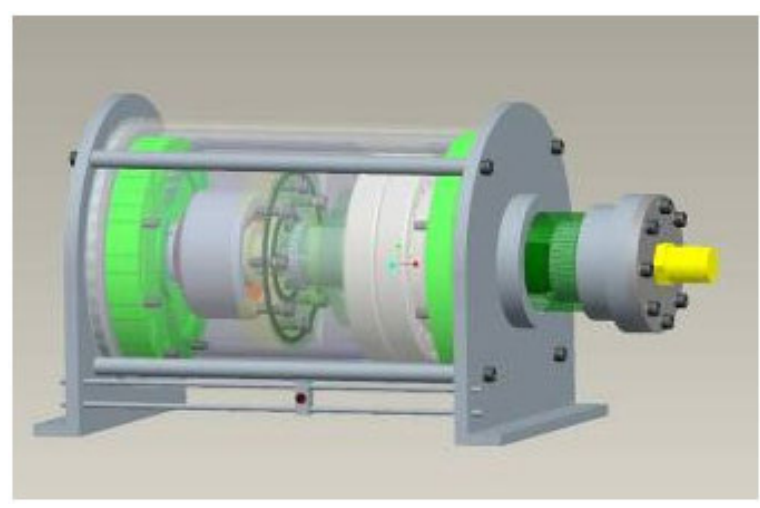

Fig. 5 The winch three-dimensional mode

After the winch three-dimensional model is constructed, we can analyze its quality characteristics, interference checking and motion simulation.

After the winch three-dimensional model is constructed, the winch motion simulation needs to be conducted to check the feasibility of the design. The movements of the winch include the rotations of the motor, the magnetic coupler and the roller. The rotation of roller completes the operation of winding rope.

In the three-dimensional design software, the winch can be carried on the movement simulation by the simulation steps, such as creating the mechanism, defining the elements, the preparation for analysis, model analysis, checking the result and so on. Meanwhile the movement process can form video data and is stored in *.mpg or *.avi format. The movement condition can be observed by the media player software and the design can be proved to be feasible by observing the motion simulation. It can also be converted from the threedimensional model to the design of engineering drawing in 
the graphic software [7].

\section{CONCLUSION}

According to the above design method of the winch, we can complete the design of the pars and make the winch prototype. The correctness and feasibility of the design can be verified by the following tests, such as spreading and rolling up the rope, tensile test, under water sealing performance testing and so on. Meanwhile the winch prototype is also prepared to conduct the sea trials in combination with other parts of the machine. As is shown in fig. 6 , part 1 is the winch and part 2 is the motor for testing. The project has passed the expert's acceptance.

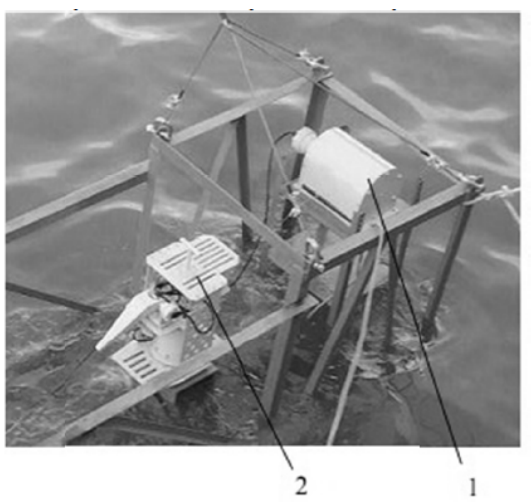

Fig. 6 The sea trials of the winch

\section{ACKNOWLEDGEMENTS}

This paper is funded by NSFC (CONTRACT NAME: Research of Analysis and Experiments of Gripping and Bearing Mechanism for Large-scale Holding and Lifting Tools on Ocean Foundation Piles ), (CONTRACT NUMBER: 51479043), the views expressed are authors' alone.'

\section{BIBLIOGRAPHY}

1. Zhou,C.C.:The technology of marine engineering on underwater connection, Journal of Beijing Institute of Petro-chemical Technology, Beijing ,2006.

2. Den N:System for subsea diverless metrology and hard-pipe connection of pipelines,United States, New York, 2004.

3. Vincent M.G.:Method of obtaining acoustic metrology data. United States, New York,,2006.

4. Cui,C.D.: Mechanical drawing,Higher Education Press, Bingjing,2004.

5. Win, J.M: Pro/E Windfire3.0 Basis of 3D design and the example of engineering, Tsinghua University Press, Beijing, 2008.

6. Wan,Q.C.: Pro/E Windfire3.0 Basis of construction, heat, movement analysis and the typical example, Publishing House of Electronics Industry, Beijing, 2008.
7. Zhao, Q.L.: SolidWorks 2006-The application examples of product design, Tsinghua University Press, Beijing,2008.

\section{CONTACT WITH THE AUTHORS}

$$
\begin{aligned}
& \text { B. Zhang } \\
& \text { Z. Wanga }{ }^{c *} \\
& \text { T. Wang } \\
& \text { H.J. Yu }
\end{aligned}
$$

${ }^{\mathrm{a} C}$ College of Mechanical and Electrical Engineering, Harbin Engineering University

\section{CHINA}

${ }^{\mathrm{b}} \mathrm{School}$ of Mechanical Engineering, Hebei University of Technology

CHINA

'College of Mechanical and Electrical Engineering, Jilin University of chemical technology

\section{CHINA}

${ }^{*}$ Corresponding author: Nantong Street No.145 in Nangang District of Harbin email: jlwzh@163.com 